\title{
Meningoencefalite por herpesvírus bovino-5 ${ }^{1}$
}

\author{
Daniel R. Rissi ${ }^{2}$, Raquel R. Rech ${ }^{2}$, Eduardo F. Flores ${ }^{3}$, Glaucia D. Kommers ${ }^{4}$ \\ e Claudio S.L. Barros ${ }^{4 *}$
}

\begin{abstract}
Rissi D.R., Rech R.R., Flores E.F., Kommers G.D. \& Barros C.S.L. 2007. [Meningoencephalitis by bovine herpesvirus-5.] Meningoencefalite por herpesvírus bovino-5. Pesquisa Veterinária Brasileira 27(7):251-260. Departamento de Patologia, Universidade Federal de Santa Maria, 97105-900, Santa Maria, RS, Brazil. E-mail: claudioslbarros@uol.com.br

Meningoencephalitis caused by bovine herpesvirus-5 (BoHV-5) is an often fatal, acute or subacute infectious disease that affects mainly young cattle under stressing conditions. The disease has been recognized in several Brazilian regions and in other parts of the world. BoHV5 is a double stranded DNA virus member of the Herpesviridae family and subfamily Alphaherpesvirinae. The virus is characterized by rapid and lytic replication in cell cultures and by the ability to establish lifelong latent infection in sensory nerve ganglia of the host. BoHV-5 is transmitted mainly by direct and indirect contact and replicates acutely in the oral, nasal, oropharingeal or ocular mucosae. After primary replication, the virus invades nerve endings and is transported to the neuron cell bodies of the sensory ganglia where it replicates actively and/or establishes latency. Viral invasion of the brain may result in massive virus replication and production of neurological disease. Virtually all cattle developing neurological disease die of meningoencephalitis; yet the infection may be subclinical in some animals. These animals recover and become latently infected. Viral dissemination within a herd is facilitated by conditions such as crowding, introduction of cattle from other herds and weaning of calves in ages that coincide with decrease of passive immunity. Certain natural or induced conditions may reactivate the latent virus and favor its transmission and dissemination to other susceptible individuals. The disease may occur as outbreaks or as sporadic cases, with morbidity rates ranging of $0.05 \%-5 \%$; lethality is almost always $100 \%$. Clinical signs include depression, nasal and ocular discharge, grinding of teeth, circling, blindness, fever, paddling movements, disphagia, abdominal pain, nystagmus, muscle tremors, drooling, incoordinated gait, opisthotonus, head pressing, falls and convulsions. Clinical course is usually 1-15 days. Necropsy findings may be absent but often there is swollen of the rostral portions of the cerebral cortex and flattening of gyri, with softening and segmental yellow discoloration (malacia). As the disease progresses the affected areas become gelatinous and grey and, in advanced cases, there is segmental loss of the cerebral cortex of the frontal lobe of the brain (residual lesion). In several cases there is malacia of the basal nuclei and of the thalamus. Histologically, there is necrotizing non-suppurative meningoencephalitis affecting mainly the cerebral cortex of the frontal lobe associated with eosinophilic intranuclear inclusion bodies in neurons and astrocytes, although the frequency of the inclusion bodies is inconsistent. The diagnosis of meningoencephalitis by BoHV-5 should be based on epidemiology, clinical signs, necropsy and histological findings. The diagnosis should be confirmed by viral isolation in cell culture and/or by detection of viral antigens in brain sections or in exfoliated cells from nasal secretions. The identification and characterization of BoHV-5 can be done by the use of mono-
\end{abstract}

${ }^{1}$ Recebido em 25 de setembro de 2006.

Aceito para publicação em 3 de abril de 2007.

Parte da Dissertação de Mestrado do primeiro autor (bolsista do CNPqConselho Nacional de Desenvolvimento Científico e Tecnológico).

2 Programa de Pós-Graduação em Medicina Veterinária, área de concentra-

\footnotetext{
ção em Patologia Veterinária, Centro de Ciências Rurais (CCR), Universidade Federal de Santa Maria (UFSM), 97105-900 Santa Maria, RS, Brasil.

${ }^{3}$ Departamento de Medicina Veterinária Preventiva, CCR, UFSM.

${ }^{4}$ Departamento de Patologia, Centro de Ciências da Saúde, UFSM. *Autor para correspondência: claudioslbarros@uol.com.br
} 
clonal antibodies, polymerase chain reaction (PCR) and/or by restriction enzyme analysis of the viral genome. There is no specific treatment for the disease. As BoHV-1 and BoHV-5 are antigenically related, vaccination using BoHV-1 vaccines may be recommended as a means of reducing the losses caused by BoHV-5 infection, mainly during outbreaks of neurologic disease. Additionally, measures such as serologic testing of new additions to the herd; and management practices to prevent stress and to reduce conditions for virus dissemination among animals may help in reducing the incidence and the consequences of BoHV-5 infection and disease.

INDEX TERMS: Bovine herpesvirus-5, BoHV-5, BHV-5, meningoencephalitis, viral diseases, diseases of cattle, neuropathology.

RESUMO.- A meningoencefalite por herpesvírus bovino-5 (BoHV-5) é uma doença infecto-contagiosa, aguda ou subaguda, geralmente fatal e que afeta principalmente bovinos jovens submetidos a situações de estresse. A doença tem sido freqüientemente diagnosticada em várias regiões do Brasil e em outras partes do mundo. BoHV-5 é um vírus da família Herpesviridae e subfamília Alphaherpesvirinae e possui como genoma uma molécula de DNA fita dupla. Esses vírus são caracterizados por rápida replicação em cultivo, que resulta em lise das células infectadas, e afetam várias espécies de hospedeiros, estabelecendo latência principalmente em neurônios de gânglios sensoriais. A transmissão de BoHV-5 ocorre principalmente por contato direto ou indireto entre bovinos. Após a replicação primária nas mucosas oral, nasal, ocular e orofaríngea, o vírus invade as terminações nervosas e é transportado até os neurônios de gânglios sensoriais, onde replica ativamente e estabelece latência. A invasão viral do encéfalo pode resultar em replicação viral massiva e produção de doença neurológica. A maioria dos bovinos que desenvolvem doença neurológica morre em decorrência de meningoencefalite, porém alguns podem desenvolver infecção subclínica e, após recuperação, permanecerem portadores da infecção latente. A disseminação viral nos rebanhos é facilitada em situações de grande concentração de animais, introdução de bovinos e desmame de lotes de bezerros em idade que coincide com o decréscimo da imunidade passiva. Certas condições, naturais ou induzidas, podem reativar o vírus do estado latente e propiciar condições para sua transmissão e disseminação a outros indivíduos. A doença pode ocorrer na forma de surtos ou em casos isolados, com coeficientes de morbidade que podem variar de $0,05 \%-5 \%$; a letalidade é quase sempre de $100 \%$. Os sinais clínicos incluem depressão, descarga nasal e ocular, ranger de dentes, andar em círculos, cegueira, febre, movimentos de pedalagem, disfagia, dor abdominal, nistagmo, tremores, sialorréia, incoordenação, opistótono, pressão da cabeça contra objetos, quedas e convulsões. A evolução do quadro clínico pode variar de 1 a 15 dias. Achados de necropsia podem estar ausentes, mas normalmente se observa tumefação das porções rostrais do córtex telencefálico e achatamento das circunvolu-ções, com segmentos amarelados e amolecidos (malacia). Com a evolução da doença, essas áreas se tornam gelatinosas e acinzentadas, e em casos avançados ocorre o desaparecimento segmentar do córtex telencefálico frontal (lesão residual). Em muitos casos podem ser observados focos de malacia na substância cinzenta dos núcleos basais e do tálamo. Histo-logicamente observa-se meningoencefalite não-supurativa necrosante, principalmente no córtex telencefálico frontal, associada a inclusões intranucleares eosinofílicas em astrócitos e neurônios, embora a freqüência dessas inclusões seja irregular. O diagnóstico de meningoencefalite por BoHV-5 deve ser feito com base nos achados epidemiológicos, clínicos, de necropsia e histopatológicos, associados com o isolamento do vírus em cultivo celular células ou com detecção de antígenos virais em seções do encéfalo ou em células descamadas presentes nas secreções nasais. A identificação e caracterização de BoHV5 pode ser realizada por meio de testes com anticorpos mono-clonais, reação em cadeia de polimerase (PCR) e por análise de restrição genômica. Não há tratamento específico para a meningoencefalite por BoHV-5. Como o BoHV-1 e o BoHV-5 são antigenicamente muito semelhantes, recomenda-se a vacinação com vacinas para BoHV-1 como forma de reduzir as perdas causadas por BoHV-5, principalmente durante surtos de doença neurológica. Adicionalmente, outras medidas podem ser adotadas para prevenir ou reduzir os prejuízos ocasionados pela enfermidade, como testar sorologicamente os bovinos a serem introduzidos nos rebanhos, minimizar situações de estresse, sobretudo no desmame, e isolamento dos bovinos afetados.

TERMOS DE INDEXAÇÃO: Herpesvírus bovino-5, BoHV-5, BHV-5, meningoencefalite, doenças a vírus, doenças de bovinos, neuropatologia.

\section{INTRODUÇÃO}

A meningoencefalite causada por herpesvírus bovino-5 (BoHV5) é uma doença infecto-contagiosa, aguda ou subaguda e geralmente fatal, que afeta principalmente bovinos jovens submetidos a situações de estresse. Essa doença tem sido freqüientemente diagnosticada em várias regiões do Brasil (Salvador et al. 1998, Colodel et al. 2002, Elias et al. 2004, Riet-Correa et al. 2006, Rissi et al. 2006). A enfermidade é causada por um vírus da família Herpesviridae, subfamília Alphaherpesvirinae e foi descrita como a segunda causa mais freqüiente de meningoencefalite viral em bovinos no Sul do Brasil (Sanches et al. 2000). O objetivo do presente trabalho é apresentar uma revisão sobre os aspectos epidemiológicos, clínicos, achados de necropsia e histopatológicos, e dos métodos de diagnóstico da meningoencefalite por BoHV-5, de modo a orientar os profissionais da área para o reconhecimento da enfermidade e a sua diferenciação de outras doenças do sistema nervoso central (SNC) de bovinos no país. 


\section{Aspectos históricos}

A meningoencefalite por BoHV-5 foi descrita pela primeira vez na Austrália (Johnston et al. 1962), embora naquela ocasião o vírus não tenha sido identificado como tal. Na época, a doença foi reproduzida em um bezerro, por inoculação intracerebral e intravenosa de material infectado proveniente dos casos naturais. Os resultados permitiram concluir que a doença havia sido causada por um agente viral e que se comportava de forma diferente de outras encefalites de bovinos descritas na época. Estudos posteriores em cultivos celulares de tecido e isolamento viral permitiram a caracterização do isolado australiano, que foi denominado N569 (French 1962a), e logo foi feita a primeira associação de N569 com o herpesvírus da rinotraqueíte infecciosa bovina (IBR). Reações sorológicas entre os dois vírus foram detectadas com o soro de cobaios imunizados, e, além disso, inclusões intranucleares morfologicamente idênticas às do vírus da IBR foram observadas em cultivos celulares (French 1962b). Após essas observações, vários surtos semelhantes de meningoencefalite em bovinos foram descritos em várias regiões do mundo (Barenfus et al. 1963, Gardiner et al. 1964, Bartha et al. 1969, Reed et al. 1973, Gough \& James 1975, Carrillo et al. 1983a, Riet-Correa et al. 1989, Weiblen et al. 1989). Em geral, todos esses surtos foram associados com o herpesvírus bovino conhecido na época (BoHV-1 ou vírus da IBR), pelas características biológicas e antigênicas do agente. Entretanto, após uma série de experimentos (Hall et al. 1966, McKercher et al. 1970), foram formuladas as primeiras hipóteses sobre a patogênese da infecção. Foi sugerida a existência de cepas neurotrópicas de BoHV-1, cuja replicação era rápida e causava doença neurológica, diferente do que ocorria na IBR ou na doença genital (vulvovaginite pustular infecciosa e balanopostite infecciosa). Essas suposições foram reforçadas após a identificação de diferenças sorológicas entre a cepa N569 e isolados de IBR (Bagust 1972). Em experimentos com inoculação intranasal e intravaginal em bovinos com amostras virais provenientes de surtos de vulvovaginite, rinite e meningoencefalite (N569), somente a última amostra foi capaz de reproduzir doença nervosa (Bagust 1972).

Até a década de 1980, a meningoencefalite por BoHV-5 foi considerada uma manifestação clinicopatológica da IBR e o vírus era classificado como um subtipo de BoHV-1 (George 1991). Estudos posteriores demonstraram diferenças em nível molecular e antigênico entre isolados de doença respiratória (IBR) e genital, comparados com os isolados de doença neurológica. $\mathrm{O}$ padrão de restrição enzimática do genoma, o perfil de polipeptídeos produzidos em células infectadas, a reatividade com anticorpos monoclonais e diferenças de neutralização claramente indicavam que os isolados de doença respiratória e genital eram diferentes dos isolados de doença neurológica (Metzler et al. 1985, 1986, Bratanich et al. 1991). Esses trabalhos levaram à classificação de BoHV-1 em três subtipos: BoHV-1.1 (doença respiratória, IBR); BoHV1.2 (doença genital) e BoHV-1.3 (doença neurológica) (Metzler et al. 1985, 1986, Bratanich et al. 1991). Em 1992, o The Herpesvirus Study Group of the International Committee on Taxonomy of Viruses reclassificou as cepas neurotrópicas como uma espécie viral distinta, denominada BoHV-5 (Roizman et al. 1992).

\section{Características do vírus e patogênese das lesões}

BoHV-5 possui como genoma uma molécula de DNA fita dupla de aproximadamente $137 \mathrm{~kb}$. 0 genoma é envolto por um capsídeo icosaédrico de aproximadamente 100-110 nm de diâmetro, que possui 12 capsômeros pentaméricos e 150 hexaméricos. O DNA e o capsídeo são envoltos por um material amorfo denominado tegumento e externamente por um envelope lipoprotéico, no qual encontram-se inseridas várias glicoproteínas virais que formam projeções (Roizman et al. 1992). Os Alphaherpesvírus são caracterizados por rápida replicação em cultivo, que resulta em lise das células infectadas, e afetam várias espécies de hospedeiros, estabelecendo latência principalmente em neurônios de gânglios sensoriais (Engels \& Ackermann 1996).

BoHV-1 e BoHV-5 são muito semelhantes em relação às suas propriedades estruturais, biológicas, antigênicas e molecu-lares, porém apresentam diferenças genéticas e imunogênicas que podem explicar as particularidades de cada um em relação à sua patogenicidade e epidemiologia (Alegre et al. 2001, Delhon et al. 2003, Hübner et al. 2005a). Doença respiratória, genital, conjuntivite e abortos são enfermidades causadas por BoHV-1. Esporadicamente esse vírus causa doença caracterizada por morbidade variável e mortalidade baixa ou nula e raramente está envolvido em casos de meningoencefalite (Furuoka et al. 1995, Roels et al. 2000, Penny et al. 2002). BoHV-5 é o agente etiológico de meningoencefalite necrosante, principalmente em bovinos jovens, e a infecção apresenta baixos ou moderados índices de morbidade e alta letalidade (Salvador et al. 1998, Colodel et al. 2002, Elias et al. 2004, Riet-Correa et al. 2006, Rissi et al. 2006).

Evidências de que o IBRV fosse o agente de doença neurológica em bovinos foram descritas no início da década de 1960 (French 1962b) e as primeiras observações em relação às diferenças entre os dois vírus foram relatadas após quase 10 anos (McKercher et al. 1970). Bezerros nascidos de vacas inoculadas experimentalmente não foram infectados nem soroconverteram ao agente, sugerindo que a transmissão ocorria de forma horizontal. Sabia-se que o vírus da IBR tinha ampla distribuição ambiental, resultando em alta exposição de bovinos ao agente, mas, apesar disso, a prevalência de casos de doença nervosa era baixa. Isso foi atribuído à falha de reconhecimento da doença nos rebanhos por veterinários. No entanto, essa hipótese é pouco provável, pois a grave doença clínica desenvolvida pelos bovinos afetados tornava improvável que um surto passasse despercebido. Outra hipótese levantada na época era de que o vírus da IBR apresentasse baixa neuroinvasividade ou que existissem algumas cepas neurotrópicas desse vírus. Essas cepas, por disseminação hematógena ou pelos nervos cranianos, invadiriam o encéfalo e produziriam meningoencefalite. Como o vírus necessitaria atravessar duas barreiras até o SNC (mucosa-circulação e circulação-SNC) e como não havia sido observada replicação do agente no sangue, seria natural que a doença nervosa ocorresse apenas raramente (McKercher et al. 1970). 
Sinais clínicos e lesões histológicas de meningoencefalite foram descritas após a inoculação intranasal (esses bovinos também desenvolveram rinite) e intracerebral de amostras $\mathrm{N} 569$ em bezerros (Hall et al. 1966). Um dos bovinos que recebeu inoculação intravaginal apresentou quadro nervoso resultante do contato focinho-vagina com outro animal inoculado pela mesma via; ambos desenvolveram vulvovaginite. Esses achados demonstraram a capacidade da amostra N569 de produzir inflamação nos locais de inoculação quando inoculada em superfícies mucosas, como a vagina e fossas nasais. Em outro experimento, quatro amostras virais australianas do vírus da IBR, isoladas de surtos de doença respiratória, vulvovaginite e meningoencefalite (N569), foram inoculadas em bezerros. As quatro amostras reproduziram inflamação nas mucosas inoculadas (nasal, vaginal e conjuntival). A inoculação intranasal do isolado N569 induziu grave doença nervosa e nenhuma das outras amostras causou distúrbios neurológicos (Bagust 1972). Resultados semelhantes foram obtidos posteriormente, quando bezerros inoculados pela via intranasal desenvolveram rinite e meningoencefalite (Bagust \& Clark 1972). Em outro experimento, bezerros inoculados com BoHV-1 desenvolveram grave doença respiratória caracterizada por rinite, faringite e pneumonia. Histologica-mente foram observados discretos focos de encefalite (Belknap et al. 1994). No entanto, atualmente se sabe que esses achados, quando isolados, podem ser interpretados como incidentais, pois focos discretos de infiltrado mononuclear perivascular podem ser observados em $30 \%$ dos encéfalos de bovinos normais (Gavier-Widen et al. 2001). No mesmo experimento (Belknap et al. 1994), bezerros inoculados com amostras de BoHV-1.3 (BoHV-5) apresentaram descarga nasal serosa, seguida de secreção mucopurulenta, anorexia e quadro neurológico grave, com convulsões, decúbito, movimentos de pedalagem e opistótono. Esses experimentos demonstraram as propriedades particulares de algumas amostras de herpesvírus bovino, isoladas de surtos de meningoencefalite, como a capacidade de causar doença nervosa em bovinos jovens. Além de causar infecção neurológica e meningoencefalite, algumas cepas de BoHV-5 produzem sinais respiratórios pronunciados quando inoculadas em bezerros (Vogel et al. 2003). Casos de aborto também foram relatados associados com surtos de doença neurológica por herpesvírus bovino (supostamente BoHV-5) (Schudel et al. 1986). Além disso, variações marcantes de neurovirulência têm sido observadas entre diferentes cepas de BoHV-5, seja em coelhos ou em bovinos (Silva et al. 1998, Caron et al. 2002, Eduardo F. Flores, observações não publicadas).

A transmissão de BoHV-5 ocorre principalmente por contato direto ou indireto entre bovinos (Engels \& Ackermann 1996), e os sítios de replicação primária são as mucosas oral, nasal, orofaríngea e ocular. Nesses locais ocorre uma fase de replicação primária em células epiteliais, após a qual o vírus invade as terminações nervosas e é transportado até neurônios de gânglios sensoriais, onde o agente pode replicar ativamente ou estabelecer latência (Engels \& Ackermann 1996). BoHV-5 pode invadir o SNC por duas vias: 1) transporte intraaxonal por nervos cranianos ou 2) hematógena. A recuperação do vírus da IBR de leucócitos de bovinos inoculados experimentalmente por via intranasal (McKercher et al. 1970) ou intracerebral (Hall et al. 1966) e de rins de bezerros inoculados via intranasal (Meyer et al. 2001) demonstrou que alguns bovinos podem desenvolver uma fase virêmica e que, desse modo, o vírus poderia ter acesso ao SNC por via hematógena. Partículas virais levadas à circulação, após adsorção em leucócitos na mucosa respiratória, chegariam ao SNC e poderiam iniciar a replicação (McKercher et al. 1970). Apesar dessa possibilidade, é mais provável que os vírions responsáveis pela infecção neurológica tenham acesso ao SNC pelas fibras nervosas distribuídas na mucosa nasal (McKercher et al. 1970). Esses vírions alcançariam o encéfalo após transporte intraaxonal retrógrado em células nervosas locais (Rock 1994, Engels \& Ackermann 1996), principalmente do bulbo olfatório e nervo trigêmeo (Beltrão et al. 2000, Meyer et al. 2001, Caron et al. 2002). A inoculação intranasal em bezerros indicou que o nervo trigêmeo pode uma via de acesso do vírus ao SNC (Bagust \& Clark 1972), mas a inoculação do vírus por via intranasal em coelhos indicou que a via olfatória é mais eficiente e mais rápida (Beltrão et al. 2000, Diel et al. 2005). A remoção cirúrgica dos bulbos olfatórios previamente à inoculação de BoHV-5 reduziu drasticamente a ocorrência de infecção e doença neurológica em coelhos, indicando que nessa espécie, a via olfatória se constitui na principal via de acesso ao SNC após replicação na cavidade nasal (Diel et al. 2005). Infecções experimentais em bovinos também suportam a hipótese de invasão pela via olfatória durante a infecção aguda (Perez et al. 2003). Em coelhos inoculados pela via conjuntival, o desenvolvimento da doença neurológica foi mais tardia, indicando que a via trigeminal também pode servir de acesso ao SNC, porém com cinética retardada (Diel et al. 2005). De fato, análises de isolamento viral e imunoistoquímica revelaram que ambas as vias de acesso (olfatório e trigêmeo) são possíveis (Meyer et al. 2001). Nesse trabalho, pôde-se observar que as reações por imunoistoquímica no bulbo olfatório e córtex frontal foram mais consistentes, o que corrobora a afirmação sobre a eficiência da via olfatória (Beltrão et al. 2000, Diel et al. 2005).

A localização e intensidade das lesões no encéfalo de bovinos afetados por meningoencefalite por BoHV-5, mais acentuadas nas porções rostrais do telencéfalo (Salvador et al. 1998, Colodel et al. 2002, Elias et al. 2004, Rissi et al. 2006), e a ausência de lesões no gânglio de Gasser de bovinos afetados pela doença (Rissi et al. 2006) fornecem fortes evidências de que a via olfatória é a principal rota de invasão do vírus no SNC em surtos espontâneos. Apesar disso, ainda existem dúvidas quanto ao papel da viremia na invasão do SNC por BoHV5 (Belknap et al. 1994, Engels \& Ackermann 1996).

Em casos de infecção por BoHV-5, ocorre invasão do SNC e produção de meningoencefalite (Engels \& Ackermann 1996) e o vírus pode inclusive atingir o gânglio e estabelecer latência sem prévia replicação epitelial, caso esteja em grande quantidade no inóculo (Rock 1994). Pode ainda estabelecer latência sem produzir sinais clínicos de meningoencefalite durante a infecção primária (Meyer et al. 2001). BoHV-5 foi detectado no sêmen de um bovino sem sinais clínicos (Esteves et al. 2003), 
demonstrando a capacidade de disseminação do vírus por contato genital ou inseminação artificial.

A latência é uma característica dos herpesvírus (Engels \& Ackermann 1996) que permite ao agente se manter por tempo indeterminado nos indivíduos infectados sem o desenvolvimento de manifestações clínicas (Stevens 1994). A capacidade de estabelecer infecções latentes é, provavelmente, a propriedade viral mais significativa a ser considerada no controle das enfermidades produzidas por esse grupo de vírus (Rock 1994). Durante a latência não há produção de proteínas virais ou de progênie viral infecciosa. Entretanto, o DNA viral pode ser detectado por PCR ou hibridização in situ no núcleo dos neurônios de gânglios sensoriais infectados (Engels \& Ackermann 1996). Em bovinos, os locais de latência incluem o gânglio do nervo trigêmeo, córtex telencefálico, mesencéfalo, ponte, cerebelo, medula e, menos freqüientemente, bulbo olfatório (Vogel et al. 2003). A reativação e excreção do vírus podem ocorrer naturalmente, em situações de estresse ou experimentalmente, após administração de dexametasona (Rock 1994). Essas situações propiciam condições para a transmissão e disseminação do agente para outros indivíduos suscetíveis (Caron et al. 2002). Após reativação o vírus replica ativamente nos gânglios sensoriais e é transportado pelos axônios em direção centrífuga, de volta aos locais de replicação primária, replica no local e é excretado (Rock 1994). Como regra, a reativação dos herpesvírus animais geralmente cursa sem sinais clínicos. No entanto, a reativação espontânea e artificial de BoHV-5 em coelhos e bovinos infectados experimentalmente tem sido freqüentemente acompanhada de recrudescência clínica e desenvolvimento de doença neurológica (Caron et al. 2002, Perez et al. 2002, Vogel et al. 2004). A recrudescência da doença neurológica que acompanha epi-

Quadro 1. Distribuição geográfica e características histopatológicas de casos espontâneos de meningoencefalite por herpesvírus bovino (sob várias denominações)

\begin{tabular}{lcl}
\hline Característica da infecção & País & \multicolumn{1}{c}{ Referência } \\
\hline Inflamatória & Austrália & Johnston et al. 1962 \\
Inflamatória & Estados Unidos & Barenfus et al. 1963 \\
Inflamatória & Austrália & Gardiner et al. 1964 \\
Inflamatória & Hungria & Bartha et al. 1969 \\
Inflamatória & Estados Unidos & Reed et al. 1973 \\
Inflamatória com malacia & Canadá & Gough \& James 1975 \\
Inflamatória com malacia & Canadá & Beck 1975 \\
Inflamatória & Escócia & Watt et al. 1981 \\
Inflamatória com malacia & Argentina & Dias et al. 1982 \\
Inflamatória com malacia & Argentina & Carrillo et al. 1983a \\
Inflamatória com malacia & Argentina & Carrillo et al. 1983b \\
Inflamatória com malacia & Brasil & Riet-Correa et al. 1983 \\
Inflamatória com malacia & Brasil & Méndez et al. 1987 \\
Inflamatória com malacia & Brasil & Riet-Correa et al. 1989 \\
Inflamatória com malacia & Brasil & Weiblen et al. 1989 \\
Inflamatória com malacia & Brasil & Schild et al. 1994 \\
Inflamatória com malacia & Brasil & Salvador et al. 1998 \\
Inflamatória com malacia & Brasil & Colodel et al. 2002 \\
Inflamatória com malacia & Argentina & Pérez et al. 2003 \\
Inflamatória com malacia & Brasil & Elias et al. 2004 \\
Inflamatória com malacia & Brasil & De Paula et al. 2005 \\
Inflamatória com malacia & Brasil & Riet-Correa et al. 2006 \\
Inflamatória com malacia & Brasil & Rissi et al. 2006 \\
& &
\end{tabular}

sódios de reativação viral poderia explicar os casos isolados de doença nervosa por BoHV-5, quando apenas um ou poucos animais do rebanho adoecem.

\section{Epidemiologia}

A meningoencefalite por herpesvírus bovino (com várias denominações usadas para designar o agente etiológico que provavelmente seria BoHV-5) foi descrita em várias regiões do mundo (Quadro 1). A enfermidade afeta principalmente bovinos jovens submetidos a situações de estresse (Johnston et al. 1962, Gardiner et al. 1964, Reed et al. 1973, Gough \& James 1975, Carrillo et al. 1983a, Riet-Correa et al. 1989, Weiblen et al. 1989, Salvador et al. 1998, Colodel et al. 2002, Elias et al. 2004, Riet-Correa et al. 2006, Rissi et al. 2006), embora possa também afetar animais adultos (Beck 1975, Vasconcelos et al. 1993, Salvador et al. 1998). A doença ocorre na forma de surtos ou de casos isolados (Salvador et al. 1998, Colodel et al. 2002, Elias et al. 2004, De Paula et al. 2005, Riet-Correa et al. 2006, Rissi et al. 2006). Casos de meningoencefalite por BoHV-1 também têm sido relatados, raramente e são idênticos aos observados na infecção por BoHV-5 (Furuoka et al. 1995, Roels et al. 2000, Penny et al. 2002). Um resumo dos dados epidemiológicos dos principais casos de meningoencefalite por herpesvírus bovino (sob várias denominações) descritos no Brasil está apresentado no Quadro 2.

A infecção natural por BoHV-5 com sinais clínicos foi descrita somente em bovinos, mas a doença já foi reproduzida em ovinos (Silva et al. 1998) e coelhos (Beltrão et al. 2000, Caron et al. 2002, Spilki et al. 2002, Diel et al. 2005). Anticorpos contra o BoHV-5 já foram detectados em ovinos (Lindner et al. 1993), indicando que essa espécie pode ser naturalmente infectada. Caprinos infectados experimentalmente desenvolveram a infeç̧ão aguda e latente, excretam o vírus após a reativação induzida por dexametasona, mas aparentemente são mais resistentes do que os bovinos e não desenvolveram a doença neurológica (Diel et al. 2007). A meningoencefalite por BoHV-5 é uma doença geralmente esporádica e fatal, ao contrário da enfermidade causada por BoHV-1, que é endêmica e apresenta baixas taxas de mortalidade (Silva et al. 1998). Alguns autores sugerem que BoHV-5 seja mais adaptado às raças zebuínas (Bos indicus) e sua transmissão ocasional a raças européias seja o fator responsável por doença fatal em uma espécie não adaptada (Studdert 1989). No entanto, são descritos surtos de meningoencefalite por BoHV-5 em rebanhos de raças zebuínas com índices de mortalidade e letalidade tão altos quanto os descritos em rebanhos de raças européias (Salvador et al. 1998, Colodel et al. 2002). Alguns autores relatam que apesar da ampla distribuição de BoHV-1 no rebanho bovino brasileiro, a prevalência de infecções por BoHV-5 não é bem documentada, devido à dificuldade de diferenciação sorológica entre BoHV-5 e outras amostras de herpesvírus (BoHV-1) remetidas aos laboratórios de diagnóstico e à variedade individual das diversas cepas estudadas em várias regiões do país (Roehe et al. 1998). Várias pesquisas têm sido desenvolvidas com o objetivo de diferenciar precisamente as diversas amostras de BoHV-5 isoladas de 


\begin{tabular}{|c|c|c|c|c|c|c|}
\hline Estado & $\begin{array}{l}\text { Evolução } \\
\text { clínica } \\
\text { (dias) }\end{array}$ & $\begin{array}{l}\text { Idade } \\
\text { (meses) }\end{array}$ & $\begin{array}{l}\text { Morbida- } \\
\text { de (\%) }\end{array}$ & $\begin{array}{l}\text { Mortali- } \\
\text { dade (\%) }\end{array}$ & $\begin{array}{l}\text { Letalida- } \\
\text { de }(\%)\end{array}$ & Referência \\
\hline RS & $\mathrm{nc}^{\mathrm{a}}$ & 1 & 30 & 22,5 & 75 & Riet-Correa et al. $1983^{b}$ \\
\hline RS & 15 & 2 & 0,7 & 0,7 & 100 & Méndez et al. 1987c \\
\hline RS & $4-7$ & $0,5-1$ & 31,7 & 24,4 & 76,9 & Riet-Correa et al. $1989^{d}$ \\
\hline RS & nc & 1 & nc & nc & nc & Weiblen et al. $1989^{c}$ \\
\hline RS & 6 & 30 & nc & nc & 100 & Vasconcelos et al. $1993^{\circ}$ \\
\hline RS & $3-4$ & 18 & 3,8 & 3,8 & 100 & Schild et al. $1994^{\mathrm{b}}$ \\
\hline MS, SP & $1-15$ & $6-60$ & $0,05-5$ & $0,05-5$ & 100 & Salvador et al. $1998^{d}$ \\
\hline MT & $3-7$ & $2-72$ & $0,1-13,3$ & $0,1-13,3$ & 100 & Colodel et al. $2002^{d}$ \\
\hline RS & $2-15$ & $2-24$ & 0,8 & 0,8 & $22,2-100$ & Elias et al. 2004d \\
\hline GO & 9 & 9 & nc & nc & nc & De Paula et al. $2005^{c}$ \\
\hline PA & $3-4$ & $12-24$ & nc & nc & nc & Riet-Correa et al. $2006^{d}$ \\
\hline RS & $1-15$ & $1-18$ & 3,9 & 3,7 & 92,6 & Rissi et al. $2006^{\mathrm{d}}$ \\
\hline
\end{tabular}

casos naturais de meningoencefalite (Souza et al. 2002, Kunrath et al. 2004, Oldoni et al. 2004, Hübner et al. 2005b).

Fatores epidemiológicos que favorecem a disseminação viral nos rebanhos incluem a grande concentração de animais, introdução de bovinos de outros locais e desmame de lotes de bezerros em idade que coincide com o decréscimo da imunidade passiva (George 1991). Certas condições, naturais ou induzidas (inoculação de dexametasona), podem reativar o vírus do estado latente e propiciar condições para sua transmissão e disseminação a outros indivíduos suscetíveis (Belknap et al. 1994). Essa reativação pode cursar de forma subclínica ou acompanhada de doença neurológica clinicamente semelhante à infecção primária (Caron et al. 2002, Vogel et al. 2003). Esses fatores de estresse têm sido observados por vários autores (Johnston et al. 1962, Gardiner et al. 1964). Nos surtos brasileiros também foram descritas situações semelhantes envolvidas com o desenvolvimento da enfermidade, como vacinação, desmame, troca de alimentação, assinalação, castração, troca de piquetes (Elias et al. 2004) e introdução de bovinos no rebanho (Colodel et al. 2002). O desmame recente de bezerros foi descrito em $75 \%$ das propriedades onde ocorreram casos de meningoencefalite por BoHV-5, porém em nenhuma ocasião foi observada uma possível falha na transferência passiva de imunidade (Rissi et al. 2006). Estudos experimentais (Belknap et al. 1994) comprovaram a ação da imunidade passiva ao demonstrarem que grupos de bezerros privados de colostro desenvolveram encefalite e doença respiratória após inoculação de BoHV-5 e BoHV-1, respectivamente. Os bezerros alimentados com colostro e inoculados com BoHV5 não apresentaram qualquer sinal nervoso ou respiratório na infecção primária. Entretanto, quando realizada administração de dexametasona no $60^{\circ}$ dia pi, esses bovinos apresentaram sinais respiratórios discretos, letargia, aumento da temperatura retal e excretaram partículas virais na secreção nasal, demonstrando a reativação viral, de modo semelhante ao que pode ocorrer em situações naturais de estresse.

A relação epidemiológica entre casos de meningoencefalite por BoHV-5 e polioencefalomalacia (PEM) é descrita no Mato Grosso do Sul, e evidências experimentais sugerem que agen- tes etiológicos da PEM possam reativar infecções latentes por BoHV-5 em bovinos (David et al. 2007). Além disso, são descritos casos experimentais de infecção por BoHV-5 em que a infecção acidental pelo vírus da diarréia viral bovina (BVD) pode ter exacerbado os sinais clínicos da infecção por BoHV5 e aumentado a quantidade de vírus excretado pela via nasal (Spilki et al. 2006). Esses autores sugerem que ambas as doenças (PEM e BVD) podem ter relação com casos de meningoencefalite por BoHV-5 em situações naturais.

A infecção e enfermidade pelo BoHV-5 já foram descritas em vários países, mas a sua ocorrência tem sido notadamente maior no Brasil e na Argentina. Uma das explicações para a baixa incidência em países europeus e norte-americanos é a de que a imunidade contra BoHV-1 naqueles países, seja por infecção natural ou por vacinação, protegeria (reação cruzada) os animais contra o BoHV-5 (Thiry et al. 2006). Os surtos seriam mais freqüientes nas regiões onde a infecção natural e/ou vacinação contra o BoHV-1 ocorrem com menor freqüência.

\section{Sinais clínicos}

A evolução do quadro clínico nos bovinos afetados por meningoencefalite por BoHV-5 varia de 1-15 dias (Johnston et al. 1962, Gardiner et al. 1964, Beck 1975, Carrillo et al. 1983a, Salvador et al. 1998, Colodel et al. 2002, Elias et al. 2004, De Paula et al. 2005, Riet-Correa et al. 2006, Rissi et al. 2006) e se inicia após um período de incubação de 7-10 dias (Gardiner et al. 1964, Reed et al. 1973, Belknap et al. 1994). Na maioria dos casos a doença é fatal, embora existam relatos de surtos em que houve recuperação de animais após o quadro clínico (Johnston et al. 1962, Gardiner et al. 1964, Elias et al. 2004, Rissi et al. 2006). Em alguns surtos, a depressão profunda pode ser o único sinal evidente em fases iniciais da doença (Halfen $\&$ Vidor 2001, Rissi et al. 2006). Os bovinos se afastam do rebanho e permanecem parados, com olhar fixo e cabeça baixa; freqüentemente apresentam corrimento nasal e ocular seroso que, com a evolução da doença, torna-se mucoso e mucopurulento. Os bovinos afetados apresentam desidratação, emagrecimento, febre, ranger de dentes, tremores musculares, andar em círculos, cegueira, incoor-denação, pres- 
são da cabeça contra objetos, nistagmo e disfagia. Alguns bovinos podem sofrer quedas e permanecer em decúbito, com movimentos de pedalagem, opistótono e convulsões. Sinais clínicos inespecíficos, como dor abdominal, anorexia, taquicardia, taquipnéia, pêlos arrepiados e melena também são descritos em casos da doença (Johnston et al. 1962, Gardiner et al. 1964, Reed et al. 1973, Kahrs 1977, Riet-Correa et al. 1989, Weiblen et al. 1989, Salvador et al. 1998, Colodel et al. 2002, Elias et al. 2004, De Paula et al. 2005, Riet-Correa et al. 2006, Rissi et al. 2006). Alguns bovinos podem desenvolver broncopneumonia (Belknap et al. 1994) e, menos freqüentemente, são relatados casos em que os bovinos apresentam agressividade (Gough \& James 1975) e sinais neurológicos designados como mania (Beck 1975).

\section{Achados de necropsia e histopatológicos}

Os bovinos afetados por meningoencefalite por BoHV-5 podem não apresentar lesões macroscópicas no encéfalo (Johnston et al. 1962, Colodel et al. 2002, Rissi et al. 2006). No entanto, freqüientemente são observados vários graus de lesões inflamatórias e degenerativas no encéfalo dos bovinos afetados (Johnston et al. 1962, Gardiner et al. 1964, Salvador et al. 1998, Colodel et al. 2002, Elias et al. 2004, De Paula et al. 2005, Riet-Correa et al. 2006, Rissi et al. 2006). As lesões não são simétricas, podem ter ampla variação entre os bovinos (Belknap et al. 1994) e são claramente mais intensas nas porções rostrais do encéfalo (Johnston et al. 1962, Gardiner et al. 1964, Salvador et al. 1998, Colodel et al. 2002, Elias et al. 2004, Rissi et al. 2006). Lesões discretas ou moderadas são caracterizadas por hiperemia difusa dos vasos das leptomeninges por toda a extensão do encéfalo (Gardiner et al. 1964, Carrillo et al. 1983a, Rissi et al. 2006); em alguns casos são descritos, além da hiperemia, edema (Dias et al. 1982) e focos de hemorragia na superfície de corte do encéfalo (Elias et al. 2004, Colodel et al. 2002). Pode ser observada tumefação das porções rostrais do telencéfalo, com achatamento e amarelamento das circunvoluções dos lobos frontais, características de malacia (Rissi et al. 2006). Com a evolução da doença, essas áreas se tornam deprimidas, gelatinosas e acinzentadas (Rissi et al. 2006), com aspecto granular ao corte (Johnston et al. 1962, Dias et al. 1982, Carrillo et al. 1983b, Colodel et al. 2002, Rissi et al. 2006). Áreas de malacia também podem ser observadas nos lobos parietais do córtex telencefálico, no tálamo e nos núcleos da base (Rissi et al. 2006). Nos casos mais avançados pode haver desenvolvimento de lesão residual, evidenciada pelo desaparecimento segmentar do córtex telencefálico frontal, com formação de uma área cística entre as leptomeninges e a substância branca subcor-tical (Rissi et al. 2006). Outros achados incluem muco nas fossas nasais, hiperemia da mucosa nasal (rinite), aumento do volume de linfonodos retrofaríngeos e mediastínicos (Dias et al. 1982, Carrillo et al. 1983a) e focos hemorrágicos na mucosa da laringe e faringe (Carrillo et al. 1983a).

Histologicamente os bovinos afetados apresentam meningoencefalite não-supurativa necrosante, que varia quanto à localização e intensidade em cada caso e em seções do encéfalo de um mesmo caso (Colodel et al. 2002, Elias et al. 2004, Rissi et al. 2006). A intensidade das lesões é mais acentuada, em ordem decrescente, na região cortical dos lobos frontais do telencéfalo, cápsula interna e núcleos da base, no tálamo, córtex parietal, mesencéfalo, na ponte, no córtex occipital, bulbo, cerebelo e hipocampo (Rissi et al. 2006). Os achados são caracterizados por infiltrado inflamatório perivascular linfoplasmocitário ou misto nos espaços de Virchow-Robin ou ao redor de vasos meníngeos, infiltração difusa de neutrófilos no neurópilo, necrose neuronal, caracterizada por encolhimento e eosinofilia do citoplasma e núcleo picnótico (Salvador et al. 1998, Colodel et al. 2002, Elias et al. 2004, Rissi et al. 2006). Inclusões intranucleares eosinofílicas em astrócitos e neurônios são descritas em todos os casos (Elias et al. 2004), na maioria dos casos (Salvador et al. 1998), ocasionalmente (Rissi et al. 2006), raramente (George 1991) ou não são encontradas (Barenfus et al. 1963, Carrillo et al. 1983b); as inclusões são mais freqüentes em áreas de inflamação e malacia (Colodel et al. 2002, Elias et al. 2004, Rissi et al. 2006).

Outros achados incluem gliose difusa ou focal, neurono-fagia e áreas focalmente extensas de necrose do componente neuroectodérmico e manutenção das estruturas mesenquimais (vasos e células da glia), características de malacia. Essas áreas são preenchidas por macrófagos volumosos e com citoplasma espumoso (células Gitter). Nos casos avançados são observadas apenas estruturas vasculares e poucas células Gitter em uma cavidade, caracterizando uma lesão residual (Rissi et al. 2006). As alterações histopatológicas são essencialmente as mesmas em todos os casos da doença (Johnston et al 1962, Carrillo et al. 1983b, Riet-Correa et al. 1989, 2006, Salvador et al. 1998, Colodel et al. 2002, Elias et al. 2004, De Paula et al. 2005, , Rissi et al. 2006), mas diferem em relação à presença ou não de malacia (Rissi et al. 2006) nos vários surtos descritos (Quadro 1). Esses padrões morfológicos podem ter origem em diferenças de neurovirulência entre cepas de BoHV-5 (Beltrão et al. 2000, Caron et al., 2002) ou nos critérios empregados pelos diferentes autores para classificar malacia (Rissi et al. 2006).

Livros texto de neuropatologia veterinária (Summers et al. 1995) relatam a ausência de lesões macroscópicas e de malacia e sequer mencionam alterações histológicas de necrose neuronal em casos de meningoencefalite por BoHV5. Ao julgar pela literatura e pelos casos acompanhados pelos autores deste trabalho, essa informação não é correta, pois apesar de alguns bovinos não apresentarem lesões macroscópicas no encéfalo, é evidente que ao se acompanhar um número razoável de casos da doença tais achados tornam-se comuns e característicos do quadro de necropsia.

\section{Diagnóstico, tratamento e controle}

O diagnóstico presuntivo de meningoencefalite por BoHV5 pode ser feito com base nos achados epidemiológicos, clínicos, de necropsia e histopatológicos (Salvador et al. 1998, Colodel et al. 2002, Elias et al. 2004, Rissi et al. 2006). No entanto, deve-se procurar confirmação pelo isolamento do vírus por detecção de antígenos virais em seções do encéfalo ou em células descamativas presentes nas secreções nasais (d'Offay et al. 1995, Kunrath et al. 2004, Oldoni et al. 2004). As alterações histopatológicas no SNC, mesmo sem a presen- 
ça de inclusões, são características o suficiente e permitem um diagnóstico de rotina em casos onde os exames virológicos não sejam possíveis.

As técnicas confirmatórias incluem o isolamento do vírus do encéfalo ou de secreções nasais (d'Offay et al. 1995) e identificação do agente por anticorpos monoclonais (Roehe et al. 1997, Almeida et al. 1998, Souza et al. 2002, Kunrath et al. 2004, Oldoni et al. 2004). A caracterização de BoHV-5 (e sua diferenciação do BoHV-1) pode ser realizada por reatividade diferencial com alguns anticorpos monoclonais antiBoHV-1 (Roehe et al. 1997) ou por reação específica com anticorpos monoclonais anti-BoHV-5 (Almeida et al. 1998, Kunrath et al. 2004, Oldoni et al. 2004). Para que o isolamento viral seja bem sucedido é importante que o material seja coletado e remetido refrigerado, ao laboratório (Colodel et al. 2002).

A imunoistoquímica é um método adequado para a identificação do agente em amostras fixadas em formol (Hübner et al. 2005, De Paula et al. 2005). A marcação por imunoperoxidase com anticorpo primário anti-BoHV-5 foi demonstrada em neurônios, células gliais e macrófagos em tecidos provenientes de casos naturais de meningoencefalite por BoHV-5 e os antígenos virais eram mais abundantes no córtex telencefálico (d'Offay et al. 1995). Pesquisadores brasileiros realizaram a otimização da técnica de imunoistoquímica para deteç̧ão de BoHV-5 em tecidos fixados em formol (Hübner et al. 2005). Nesse estudo os antígenos virais foram detectados em neurônios, células gliais e células mononu-cleares do infiltrado perivascular.

Técnicas moleculares (PCR) também podem ser empregadas para deteç̧ão e diferenciação entre BoHV-1 e BoHV-5 de amostras isoladas em laboratório ou provenientes de casos clínicos (Ashbaugh et al. 1997, Alegre et al. 2001, Claus et al. 2005). Também foram desenvolvidos ensaios de análise de restrição genômica (D'Arce et al. 2002) e análise de polimorfismo de DNA para a diferenciação entre cepas de BoHV-1 e BoHV-5 (Afonso et al. 2007).

Não há tratamento específico para a meningoencefalite por BoHV-5 (George 1991) e o número de bovinos afetados que se recupera em um surto é muito baixo (Rissi et al. 2006). Não são descritas medidas de controle e profilaxia aplicadas diretamente à infecção por BoHV-5, porém vários trabalhos demonstram reatividade sorológica e proteção cruzada entre BoHV-1 e BoHV-5 (Cascio et al. 1999, Beltrão et al. 2000, Vogel et al. 2002, Del Médico Zajac et al. 2006).

Como BoHV-1 e BoHV-5 são antigenicamente muito semelhantes, anticorpos neutralizantes produzidos contra BoHV1 reagem e neutralizam BoHV-5 em níveis semelhantes in vitro, e vice-versa (Vogel et al. 2002). Essa reatividade sorológica cruzada tem sido demonstrada in vitro e também in vivo (Del Médico et al. 2006). Bezerros previamente imunizados ou infectados naturalmente com uma amostra de BoHV-1 e posteriormente inoculados por via intranasal com uma amostra de BoHV-5 não desenvolveram sinais de meningoencefalite (Cascio et al. 1999). Coelhos imunizados com uma amostra de BoHV-5 ou de BoHV-1 também não desenvolveram doença clínica após desafio com BoHV-5 (Beltrão et al. 2000). Em ou- tro estudo foi demonstrado que anticorpos neutralizantes anti-BoHV-5 produzidos no soro de bovinos imunizados com vacinas anti-BoHV-1 neutralizaram ambos os vírus em diluições equivalentes (Vogel et al. 2002). Um estudo recente demonstrou que bovinos adequadamente imunizados contra BoHV-1 ficam protegidos da infecção por BoHV-5 (Del Médico et al. 2006). Com isso, mesmo na ausência de vacinas específicas contra BoHV-5, poderia ser recomendada a vacinação com imunógenos para BoHV-1 como forma de reduzir as perdas causadas por aquele vírus. De fato, a vacinação do rebanho é preconizada durante a ocorrência de casos de meningoencefalite por BoHV-5 (Salvador et al. 1998).

No Brasil existem várias vacinas contendo antígenos de BoHV-1 e uma vacina de fabricação nacional contém antígenos dos dois vírus. A maioria dessas vacinas contém antígenos inativados e por isso requerem múltiplas aplicações para se atingir níveis adequados de proteção.

Além da vacinação, outras medidas podem ser adotadas para prevenir ou reduzir os prejuízos ocasionados pela enfermidade. Dentre essas medidas recomenda-se: i) testar sorologicamente os animais a serem introduzidos nos rebanhos, ii) minimizar as situações de estresse, sobretudo no desmame, e iii) isolar os animais afetados. Em rebanhos com um número limitado de animais sorologicamente positivos, a identificação e o descarte destes animais podem ser recomendados como forma de erradicar definitivamente a infecção da propriedade.

\section{REFERÊNCIAS}

Afonso D.A.F., Ortega L.S., Redondo R.A.F., Trindade G.F. \& Barbosa-Stancioli E.F. 2007. Characterization on field bovine herpesvirus samples using random amplified polymorphic DNA (RAPD). J. Virol. Meth. 140:200-205.

Alegre M., Nanni M. \& Fondevila N. 2001. Development of a multiplex polymerase chain reaction for the differentiation of bovine herpesvirus-1 and 5. J. Vet. Med. 48:613-621.

Almeida R.S., Melo S.V., Silva T.C., Oliveira L.G., Lemos R.A.A. \& Roehe P.M. 1998. Anticorpos monoclonais contra o herpesvírus bovino tipo 5 (BHV-5). Pesq. Agropec. Gaúcha 4:67-72.

Ashbaugh S.E., Thompson K.E., Belknap E.B., Schultheiss P.C., Chowdhury S. \& Collins J.K. 1997. Specific detection of shedding and latency of bovine herpesvirus 1 and 5 using a nested polymerase chain reaction. J. Vet. Diag. Invest. 9:387-394.

Bagust T.J. 1972. Comparision of the biological, biophysical and antigenic properties of four strains of infectious bovine rhinotracheitis herpesvirus. J. Comp. Path. 82:365-374.

Bagust T.J. \& Clarck L. 1972. Pathogenesis of meningoencephalitis produced in calves by infectious bovine rhinotracheitis herpesvirus. J. Comp. Path. 82:375-383.

Barenfus M., Delli Quadri C.A., McIntyre R.W. \& Schroeder R.J. 1963. Isolation of infectious bovine rhinotracheitis virus from calves with meningoencephalitis. J. Am. Vet. Med. Assoc. 143:725-728.

Bartha A., Hadju G., Áldásy P. \& Paczolay G. 1969. Occurrence of encephalitis caused by infectious bovine rhinotracheitis virus in calves in Hungary. Acta Vet. Acad. Scient. Hung. 19:145-151.

Beck B.E. 1975. Infectious bovine rhinotracheitis encephalomyelitis in cattle and its differential diagnosis. Can. Vet. J. 16:269-271.

Belknap E.B., Collins J.K., Ayers V.K. \& Schultheiss P.C. 1994. Experimental infection of neonatal calves with neurovirulent bovine herpesvirus type 1.3. Vet. Path. 31:358-365.

Beltrão N., Flores E.F., Weiblen R., Silva A.M., Roehe P.M. \& Irigoyen L.F. 2000. 
Infecção e enfermidade neurológica pelo herpesvírus bovino tipo 5 (BHV5): coelhos como modelo experimental. Pesq. Vet. Bras. 20:144-150.

Bratanich A.C., Sardi S.I., Smitsaart E.N. \& Schudel A.A. 1991. Comparative studies of BHV-1 variants by in vivo-in vitro tests. J. Vet. Med. B 38:41-48.

Caron L., Flores E.F., Weiblen R., Scherer C.F., Irigoyen L.F., Roehe P.M., Odeon A. \& Sur J.H. 2002. Latent infection by bovine herpesvirus type-5 in experimentally infected rabbits: virus reactivation, shedding and recrudescence of neurological disease. Vet. Microbiol. 84:285-295.

Carrillo B.J., Ambrogí A., Schudel A.A., Vazquez M., Dahme E. \& Pospischil A. 1983a. Meningoencephalitis caused by IBR virus in calves in Argentina. Zbl. Vet. Med. B 30:327-332.

Carrillo B.J., Pospischil A. \& Dahme E. 1983b. Pathology of a bovine necrotizing encephalitis in Argentina. Zbl Vet. Med. B 30:161-168.

Cascio K.E., Belknap E.B., Schultheiss P.C., Ames A.D. \& Collins J.K. 1999. Encephalitis induced by bovine herpesvirus 5 and protection by prior vaccination or infection with bovine herpesvirus 1 . J. Vet. Diagn. Invest. 11:134-139.

Claus M.P., Alfieri A.F., Folgueras-Flatschart A.V., Wosiacki S.R., Medici K.C. \& Alfieri A.A. 2005. Rapid detection and differentiation of bovine herpesvírus 1 and 5 glycoprotein $\mathrm{C}$ gene in clinical specimens by multiplex-PCR. J. Virol. Meth. 128:183-188.

Colodel E.M., Nakazato L., Weiblen R., Mello R.M., Silva R.R.P., Souza M.A., Filho J.A.O. \& Caron L. 2002. Meningoencefalite necrosante em bovinos causada por herpesvírus bovino no estado de Mato Groso do Sul, Brasil. Ciência Rural, Santa Maria, 32:293-298.

D'Arce R.C.F., Almeida R.S., Silva T.C., Franco A.C., Spilki F., Roehe P.M. \& Arns C.W. 2002. Restriction endonuclease and monoclonal antibodies analysis of Brazilian isolates of bovine herpesvirus types 1 and 5. Vet. Microbiol. 88-315-324.

d'Offay J.M., Ely R.W., Baldwin C.A., Whitenack D.L., Stair E.L. \& Collins J.K. 1995. Diagnosis of encephalitic bovine herpesvirus type 5 (BHV-5) infection in cattle: virus isolation and immunohistochemical detection of antigen in formalin-fixed bovine brain tissues. J. Vet. Diag. Invest. 7:247-251.

David N., Hübner S.O., Riet-Correa F., Halfen D. \& Lemos R.A. 2007. Reactivation of latent bovine herpesvirus type 5 in cattle with polioencephalomalacia induced by ammonium sulphate. Pesq. Vet. Bras. (Submetido).

De Paula R.R., Souza M.A., Colodel E.M., Hübner S.O., Brum K.B., Jorge K.B.C. \& Damasceno A.D. 2005. Meningoencefalite causada pelo BHV-5 em um bovino no Estado de Goiás. Arq. Bras. Med. Vet. Zoot. 57 (Supl.1):2.

Del Médico Zajac M.P., Puntel M., Zamorano P.I., Sadir A.M. \& Romera S.A. 2006. BHV-1 vaccine induces cross-protection against BHV-5 disease in cattle. Res. Vet. Sci. 81:327-334.

Delhon G., Moraes M.P., Lu Z., Afonso C.L., Flores E.F., Weiblen R., Kutish G.F. \& Rock D.L. 2003. Genome of bovine herpesvirus 5. J. Virol. 77:10339-10347.

Dias L.E., Maisonnave J., Guarino H., Paullier C., Perdomo E., Figares A. \& Izaguirre R. 1982. Rinotraqueitis infecciosa bovina (IBR) descripcion de um cuadro clinico em terneros de tambo. In: Anais III Congr. Nac. Veterinária, Montevideo. Sociedad de Medicina Veterinaria Del Uruguay, Montevideo, p.521-530.

Diel D.G., Fonseca E.T., Souza S.F., Mazzanti A., Bauermann F., Weiblen R. \& Flores E.F. 2005. O herpesvírus bovino tipo 5 (BoHV-5) pode utilizar as rotas olfatória ou trigeminal para invadir o sistema nervoso central de coelhos, dependendo da via de inoculação. Pesq. Vet. Bras. 25:164-170.

Diel D.G., Almeida S.R., Brum M.C.S., Dezengrini R., Weiblen R. \& Flores E.F. 2007. Acute and latent infection by bovine herpesvirus type 5 in experimentally infected goats. Vet. Microbiol. (Em publicação)

Elias F., Schild A.L. \& Riet-Correa F. 2004. Meningoencefalite e encefalomalacia por herpesvírus bovino-5: distribuição das lesões no sistema nervoso central de bovinos naturalmente infectados. Pesq. Vet. Bras. 24:123-131.

Engels M. \& Ackermann M. 1996. Pathogenesis of ruminant herpesvirus infections. Vet. Microbiol. 53:3-15.

Esteves P.A., Spilki F.R., Franco A.C., Silva T.C., Oliveira E.A.S., Moojen V.,
Esmeraldino A.M. \& Roehe P.M. 2003. Bovine herpesvirus type 5 in the semen of a bull not exhibiting clinical signs. Vet. Rec. 24:658-659.

French E.L. 1962a. A specific virus encephalitis in calves: isolation and characterization of the causal agent. Aust. Vet. J. 38:216-221.

French E.L. 1962b. Relationship between infectious bovine rhinotracheitis (IBR) virus and a virus isolated from calves with encephalitis. Aust. Vet. J. 38:555-556.

Furuoka H., Izumida N., Horiuchi M. \& Osame S. 1995. Bovine herpesvirus meningoencephalitis association with infectious bovine rhinotracheitis (IBR) vaccine. Acta Neuropathol. 90:565-571.

Gardiner M.R., Nairn M.E. \& Sier M. 1964. Viral meningoencephalitis of calves in Western Australia. Aust. Vet. J. 40:225-228.

Gavier-Widen D., Wells G.A., Simmons M.M., Wilesmith J.W. \& Ryan J. 2001 Histological observations on the brains of symptomless 7-year-old cattle. J. Comp. Path. 124:52-59.

George L.W. 1991. Understanding the encephalitic form of infectious bovine rhinotracheitis. Food Animal Practice, March:335-337.

Gomes L.I., Rocha M.A., Costa E.A., Lobato Z.I.P., Mendes L.C.N., Borges A.S., Leite R.C. \& Barbosa-Stancioli E.F. 2002. Detecção de herpesvírus bovino 5 (BoHV-5) em bovinos do sudeste brasileiro. Arq. Bras. Med. Vet. Zootec. 54:217-220.

Gough A. \& James D. 1975. Isolation of IBR virus from a heifer with meningoencephalitis. Vet. J. 16:313-314.

Halfen D.C. \& Vidor T. 2001. Infecções por herpesvírus bovino-1 e herpesvírus bovino-5. In: Riet-Correa F., Schild A.L., Méndez M.C. \& Lemos R.A.A., p.97108. (ed.), Doenças de Ruminantes e Eqüinos. Vol.1. Varela, São Paulo.

Hall W.T.K., Simmons G.C., French E.L., Snowdon W.A. \& Asdell M. 1966. The pathogenesis of encephalitis caused by the infectious bovine rhinotracheitis. Aust. Vet. J. 42:229-237.

Hübner S.O., Oliveira A.P., Franco A.C., Esteves P.A., Silva A.D., Spilki F.R., Rijsewijk F.A.M. \& Roehe P.M. 2005a. Experimental infection of calves with a gI, gE, US9 negative bovine herpesvirus type 5. Comp. Immunol. Microbiol. Infect. Dis. 28:187-196.

Hübner S.O., Pescador C., Corbellini L.G., Driemeier D., Spilki F.R. \& Roehe P.M. 2005b. Otimização da imunoistoquímica para detecção de herpesvírus bovino tipo 5 (BHV-5) em tecidos do sistema nervoso central fixados com formaldeído. Arq. Bras. Med. Vet. Zootec. 57:1-6.

Johnston L.A.Y., Simmons G.C. \& McGavin M.D. 1962. Viral meningoencephalitis in calves. Aust. Vet. J. 38:207-215.

Kahrs R.F. 1977. Infectious bovine rhinotracheitis: a review and update. J. Am. Vet. Med. Assoc. 171:1055-1064.

Kunrath C.F., Vogel F.S.F., Oldoni I., Flores E.F., Weiblen R., Dezengrini R., Torres F.D. \& Pan K.A. 2004. Soroneutralização e imunofluorescência utilizando anticorpos monoclonais no diagnóstico rápido de infecções pelo herpesvírus bovino tipos 1 e 5 (BHV-1 e BHV-5). Ciência Rural, Santa Maria, 34:1877-1883.

Lindner A., Ambrosius H. \& Liebermann H. 1993. Comparative studies on detection of BHV-5 antibodies in sheep with ELISA, serum neutralization, cell assay and immunofluorescence assay. Dtsch. Tierärztl. Wschr. 100:440442.

McKercher D.G., Bibrack B. \& Richards W.P.C. 1970. Effects of the infectious bovine rhinotracheitis virus on the central nervous system of cattle. J. Am. Vet. Med. Assoc. 156:1460-1467.

Méndez M.C., Riet-Correa F., Schild A.L. \& Ferreira J.L.M. 1987. Laboratório Regional de Diagnóstico, doenças diagnosticadas no ano 1986. Editora Universitária, Pelotas. 40p.

Metzler A.E., Matile H., Gassman U., Engels M. \& Wyler R. 1985. European isolates of bovine herpesvirus 1: A comparison of restriction endonuclease sites, polypeptides, and reactivity with monoclonal antibodies. Arch. Virol. 85:57-69.

Metzler A.E., Schudel A.A. \& Engels M. 1986. Bovine herpesvirus 1: molecular and antigenic characteristics of variant viruses isolated from calves with neurological disease. Arch. Virol. 87:205-217. 
Meyer G., Lemaire M., Ros C., Belak K., Gabriel A., Cassart D., Coignoul F., Belak S. \& Thiry E. 2001. Comparative pathogenesis of acute and latent infections of calves with bovine herpesvirus types 1 and 5 . Arch. Virol. 146:633-652.

Oldoni I., Weiblen R., Inkelmann M.A. \& Flores E.F. 2004. Production and characterization of monoclonal antibodies to a Brazilian bovine herpesvirus type 5. Braz. J. Med. Biol. Res. 37:213-221.

Penny C.D., Howie F., Nettleton P.F. \& Schock A. 2002. Upper respiratory disease and encephalitis in neonatal beef calves caused by bovine herpesvirus type 1. Vet. Rec. 151:89-91.

Perez S.E., Bretschneider G., Leunda M.R., Osorio E.A., Flores E.F. \& Odeon A.C. 2002. Primary infection, latency, and reactivation of bovine herpesvirus type 5 in bovine nervous system. Vet. Path. 39:437-444.

Pérez S.E., Vagnozzi A., Sur J.H., Odriozola E., Campero C.M. \& Odeon A.C. 2003. Retrospective analysis of cases with a diagnosis of cerebrocortical necrosis and its relation with type 5 bovine herpesvírus. Revta Arg. Microbiol. 35:69-73.

Reed D.E., Bicknell E.J. \& Bury R.J. 1973. Systemic form of infectious bovine rhinotracheitis in young calves. J. Am. Vet. Med. Assoc. 156:753-755.

Riet-Correa F., Schild A.L., Méndez M.C., Oliveira J.A., Gil-Turnes C. \& Gonçalves A. 1983. Atividades do Laboratório Regional de diagnóstico e doenças da área de influência no período 1978-1982. Editora Universitária, Pelotas. 98p.

Riet-Correa F., Vidor T., Schild A.L. \& Méndez M.C. 1989. Meningoencefalite e necrose do córtex cerebral em bovinos por herpesvírus bovino-1. Pesq. Vet. Bras. 9:13-16.

Riet-Correa G., Duarte M.D., Barbosa J.D., Oliveira C.M.C., Cerqueira V.D., Brito M.F. \& Riet-Correa F. 2006. Meningoencefalite e polioencefalomalacia causada por Herpesvírus bovino-5 no Estado do Pará. Pesq. Vet. Bras. 26:44-46.

Rissi D.R., Oliveira F.N., Rech R.R., Pierezan F., Lemos R.A.A. \& Barros C.S.L. 2006. Epidemiologia, sinais clínicos e distribuição das lesões encefálicas em bovinos afetados por meningoencefalite por herpesvírus bovino-5. Pesq. Vet. Bras. 26:123-132.

Rock D.L. 1994. Latent infection with bovine herpesvirus type 1. Sem. Virol. 5:233-240.

Roehe P.M., Silva T.C., Nardi N.B., Oliveira L.G. \& Rosa J.C.A. 1997. Diferenciação entre o vírus da rinotraqueíte infecciosa bovina (BHV-1) e o herpesvírus da encefalite bovina (BHV-5) com anticorpos monoclonais. Pesq. Vet. Bras. 17:41-44.

Roehe P.M., Teixeira M.F.B. \& Almeida R.S. 1998. Situação do BHV-1 e BHV-5 no Brasil, p.89-96. In: Anais Simpósio Internacional sobre Herpesvírus Bovino (Tipo 1 e 5) e Vírus da Diarréia Viral Bovina (BVDV), Santa Maria. Pallotti, Santa Maria, RS.

Roels S., Charlier G., Letellier C., Meyer G., Schynts F., Kerkhofs P., Thiry E. \& Vanopdenbosch E. 2000. Natural case of bovine herpesvirus 1 meningoencephalitis in an adult cow. Vet. Rec. 146:586-588.

Roizman B., Desrosiers R.C., Fleckenstein B., Lopez C., Minson A.C. \& Studdert M.J. 1992. The family herpesviridae: an update. Arch. Virol. 123:425-449.

Salvador S.W.C., Lemos R.A.A., Riet-Correa F., Roehe P.M. \& Osório A.L.A.R. 1998. Meningoencefalite em bovinos causada por herpesvírus bovino-5 no Mato Grosso do Sul e São Paulo. Pesq. Vet. Bras. 18:76-83.

Sanches A.W.D., Langohr I.M., Stigger A.L. \& Barros C.S.L. 2000. Doenças do sistema nervoso central em bovinos no sul do Brasil. Pesq. Vet. Bras. 20:113118.

Schild A.L., Riet-Correa F., Pereira D.B., Ladeira R. \& Raffi M.B. 1994. Doenças diagnosticadas pelo Laboratório Regional de Diagnóstico em 1993. Boletim do Laboratório Regional de Diagnóstico. Editora Universitária, Pelotas. 45p.

Schudel A.A., Carrillo B.J., Wyler R. \& Metzler A.E. 1986. Infections of calves with antigenic variants of bovine herpesvirus 1 (BHV-1) and neurological disease. J. Vet. Med. B 33:303-310.

Silva A.M., Flores E.F., Weiblen R., Botton S.A., Irigoyen L.F., Roehe P.M., Brum M.C.S. \& Canto M.C. 1998. Infecção aguda e latente em ovinos inoculados com herpesvírus bovino 5 (BHV-5). Pesq. Vet. Bras. 18:99-106.

Souza V.F., Melo S.V., Esteves P.A., Schmidt C.S., Gonçalves D.A., Schaefer R., Silva T.C., Almeida R.S., Vicentini F., Franco A.C., Oliveira E.A., Spilki F.R., Weiblen R., Flores E.F., Lemos R.A., Alfieri A.A., Pituco E.M. \& Roehe P.M. 2002. Caracterização de herpesvírus bovinos tipos 1 (BHV-1) e 5 (BHV-5) com anticorpos monoclonais. Pesq. Vet. Bras. 22:13-18.

Spilki F.R., Esteves P.A., Franco A.C., Lima M., Holz C.L., Batista H.B.C.R., Driemeier D., Flores E.F., Weiblen R. \& Roehe P.M. 2002. Neurovirulência e neuroinvasividade de herpesvírus bovinos tipos 1 e 5 em coelhos. Pesq. Vet. Bras. 22:58-63.

Spilki F.R., Silva T.C., Esteves P.A., Teixeira M.B., Batista H.B.C.R., Chiminazzo C., Driemeier D., Franco A.C. \& Roehe P.M. 2006. Co-infections with bovine herpesvirus type 5 and bovine viral diarrhoea virus. Arq. Bras. Med. Vet. Zootec. 5:699-707.

Stevens J.G. 1994. Overview of herpesvirus latency. Sem. Virol. 5:191-196. Studdert M.J. 1989. Bovine encephalitis herpesvirus. Vet. Rec. 125:584.

Summers B.A., Cummings, J.F. \& de Lahunta A. 1995. Inflammatory diseases of the central nervous system. p. 95-188. In: Ibid (ed.) Veterinary Neuropathology. Mosby, St Louis, Missouri. 527p.

Thiry J., Keuser V., Muylkens B., Meurens F., Gogev S., Vanderplasschen A. \& Thiry E. 2006. Ruminant alphaherpesvirus related to bovine herpesvirus 1 . Vet. Res. 37:169-190.

Vasconcelos R.O., Varaschin M.S., Wouters F., Nobre V.M.T. \& Barth A.T. 1993. Meningoencefalite Bovina por Herpesvírus. Anais VI Encontro Nacional de Patologia Veterinária, Santa Maria. 40 p.1993.

Vogel F.S.F., Caron L., Flores E.F., Weiblen R., Winkelmann E.R., Mayer S.V. \& Bastos R.G. 2003. Distribution of bovine herpesvirus type 5 DNA in the central nervous system of latently, experimentally infected calves. J. Clin. Microbiol. 41:4512-4520.

Vogel F.S.F., Flores E.F., Weiblen R. \& Kunrath C.F. 2002. Atividade neutralizante anti-herpesvírus bovino tipos 1 (BHV-1) e 5 (BHV-5) no soro de bovinos imunizados com vacinas contra o BHV-1. Ciência Rural, Santa Maria, 32:881883.

Vogel F.S.F., Lima M., Flores E.F., Weiblen R., Winkelmann E.R., Mayer S.V., Mazzutti K.C. \& Arenhart S. 2004. Replicação e excreção viral durante a infecção aguda e após a reativação da latência induzida por dexametasona em bezerros inoculados com os herpesvírus bovinos tipo 1 (BHV-1) e 5 (BHV-5). Ciência Rural, Santa Maria, 34:1619-1621.

Watt J.A., Johnston W.S., Macleod N.S. \& Borlow R.M. 1981. Infectious bovine rhinotracheitis encephalitis. Vet. Rec. 108:63-64.

Weiblen R., Barros C.S.L., Canabarro T.F. \& Flores E.F. 1989. Bovine meningoencephalitis from IBR virus. Vet. Rec. 124:666-667. 